\title{
Statistical analysis of a survey about diffusion of binge drinking and drunkorexia among students in Palermo
}

\author{
Fabio Venturella, ${ }^{1}$ Giulia Cancellieri, ${ }^{1}$ Marco Giammanco, ${ }^{2}$ Anastasia Valentina Liga ${ }^{1}$ \\ ${ }^{1}$ Biological, Chemical and Pharmaceutical Science and Technologies Department; ${ }^{2}$ Department of Experimental \\ Biomedicine and Clinical Neurosciences, University of Palermo, Italy
}

\begin{abstract}
Youth alcohol consumption is a major global public health concern. Previous reviews have concluded that exposure to alcohol marketing was associated with drinking initiation and higher alcohol consumption among youth. From January to May 2017, a survey has been conducted through administration of questionnaires about the diffusion of Binge Drinking and Drunkorexia among the students of Palermo. Test was administered, during school time, to 2331 students between the ages of 13 and 20 . Regarding the analysis of the questionnaires, $97,8 \%$ of student declares to have drunk at least once: their first taste of alcoholic drink happens at the age of thirteen/fourteen. They prefer to drink at the disco or pub (48\% disco; $22 \%$ pub) on Friday and Saturday evening (92\%). 52\% of students also declare to associate alcohol to cigarette smoking. Another important statistic is that 736 girls and 61 boys declare to prefer to restrict food intake
\end{abstract}

Correspondence: Anastasia Valentina Liga and Fabio Venturella, Biological, Chemical and Pharmaceutical Science and Technologies Department, University of Palermo, Via Archirafi 20, 90123 Palermo, Italy.

Tel.: +39.091.23891265.

E-mail: ania.liga90the@gmail.com

Key words: Binge drinking; Drunkorexia; Information; Prevention.

Contributions: the authors contributed equally.

Conflict of interest: the authors declare no potential conflict of interest.

Funding: none.

Conference presentation: part of this paper was presented at the National SIBS Congress, Trapani, Italy, 27 October 2017.

Received for publication: 24 May 2018.

Accepted for publication: 27 June 2018.

(C) Copyright F. Venturella et al., 2018

Licensee PAGEPress, Italy

Journal of Biological Research 2018; $91: 7579$

doi:10.4081/jbr.2018.7579

This article is distributed under the terms of the Creative Commons Attribution Noncommercial License (by-nc 4.0) which permits any noncommercial use, distribution, and reproduction in any medium, provided the original author(s) and source are credited. in order to consume greater quantities of alcohol and to avoid weight gain. In order to evaluate youth alcohol consumption in a different contest, it was created an online survey thanks to Google forms. This study involved 500 young people from Palermo between the ages of 19 and 30. The extrapolation of data confirmed the same results of the questionnaires on paper. In this test, however, it was also evaluated the spreading of drink-driving $(68,5 \%)$. The present survey suggests that there is an expansion of such practices in young population. In conclusion, it appears necessary to adopt measures of information and prevention to reduce territorial diffusion.

\section{Introduction}

This survey is included in the large prevention project called Prevention and Information about New and Rape Drugs, Addictions and Amateur Doping sponsored by University of Palermo, Municipality of Palermo, Federfarma-Utifarma and Health department of Sicilian Region. The objective of study was the analysis of diffusion of behaviors that can led to the phenomena of Binge Drinking and Drunkorexia among students between 13 and 20 . We decided specifically to analyze this age group because the propulsion of some subjects to assume behaviors dangerous for their health appears to be particularly high during the adolescent phase. The latter is in fact a period of intense neurocognitive development that leads to changes for the purpose of behavior, affectivity, research and selection of more rewarding stimuli: the result is an increase in the predisposition to assume risky attitudes such as alcohol abuse. It is as if the psyche during adolescence was exposed, without protective filters, to an unknown hardly tamable and this is mainly due to an imbalance that occurs between the structures commonly called Drive (subcortical structures) and Controller (prefrontal cortex): the effect of this imbalance is of poor behavioral control capacity associated with high rewarding ability. In addition, the prefrontal regions, which are responsible fort decision making, develop later in mesolimbic regions, which are responsible instead for emotional impulses and craving towards gratifying stimuli: in total there will be alterations in the systems of gratification and, at the same time, effectiveness in the prefrontal control of impulses.

The alcohol-related problems are so widespread in the juvenile population that they are considered a real health emergency. They are eradicated in today's society and are considered normal behavior. In fact, in recent decades, two types of abuse related to it have spread among young people, such as Binge Drinking (drinking to get drunk) and Drunkorexia. ${ }^{1-10}$ 


\section{Materials and Methods}

In order to obtain information related to the epidemiology of the aforementioned phenomena and to the risks related to the problems, we created a questionnaire divided into sixteen questions related to drinking habits to find attitudes related to Binge Drinking and Drunkorexia. We administered this test individually and anonymously during school hours, in the period between January and May 2017, to students aged 13 to 20 years. The analyzed sample was 2331 students from Palermo (1882 females and 949 males). This survey involved the following secondary institutes of second degree: G. Meli and Vittorio Emanuele II Classical Gymnasium, G. Galilei Scientific High School, C. Finocchiaro Aprile State Teaching Institute, Francesco Ferrara Higher Education Institute, Francesco Paolo Cascino School of Hotel Management, Luigi Einaudi Commercial School, Catalano Artistic High School, De Cosmi Language High School.

We also created another online-questionnaire with the purpose to extend the survey to all territorial young people between the ages 19 and 30 .

We have extrapolated the data through the questionnaires by creating a worksheet on Microsoft Excel and subsequent descriptive statistical analysis (Microsoft Excel).

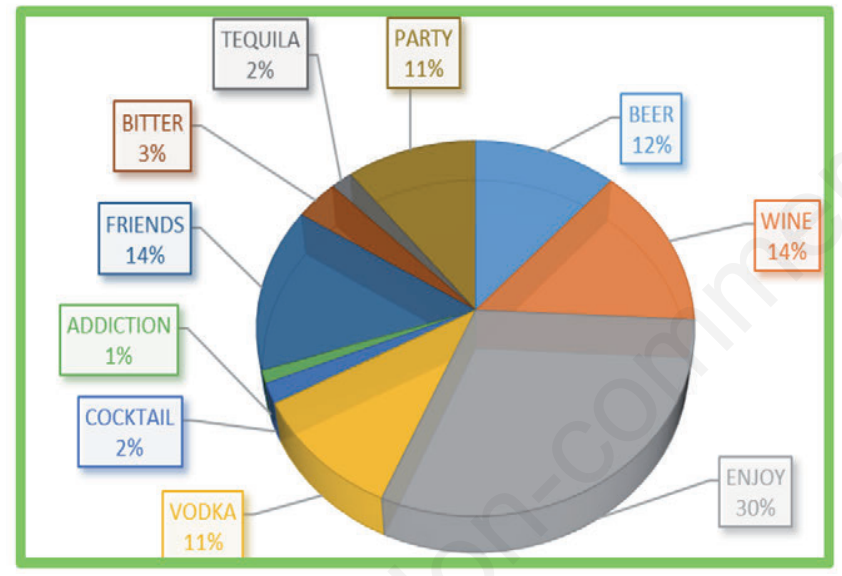

Figure 1. First alcohol-associated thought.

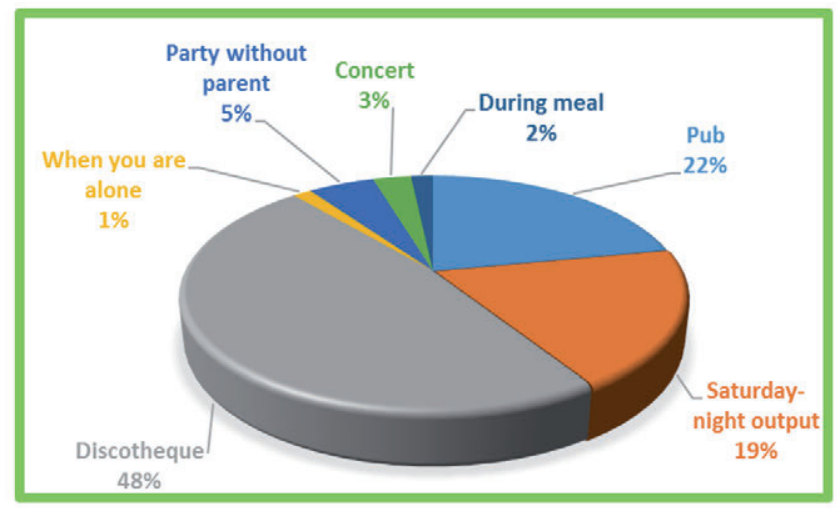

Figure 2. Most common drinking-place for young.

\section{Results and Discussion}

Through the analysis of questionnaires, we obtained some important results. 209 young people started to drink since we were 11 years old, 394 since we were twelve, 609 since we were thirteen and only 178 since we were seventeen. First young alcohol-associated thought is Enjoy (30\%), Wine (14\%), Friends (14\%), Beer $(12 \%)$ and Vodka (11\%) (Figure 1).

Young people prefer drinking with friends at the Discotheque (48\%), Pub (22\%) or during Saturday-night output (19\%) (Figure 2).

Another important data is the number of respondents who declared to get drunk during last year (94\%). The reasons that allow for such behaviors are: Transgress (17\%), Adapting to the group (17\%), Have fun (15\%), Forget problems (12\%) (Figure 3).

According to young people from Palermo, moderate consumption of alcohol is to drink three or more glasses of wine, beer or spirits ( 855 boys out of 2831 )

In order to look for behaviors related to the phenomenon of Drunkorexia, a precise question has been asked. 895 girls prefer to reduce caloric intake rather than give up drinking. Moreover, this phenomenon does not only concern female subjects but also boys: in fact, 74 boys declare they prefer to give up food but not drink (Figure 4).

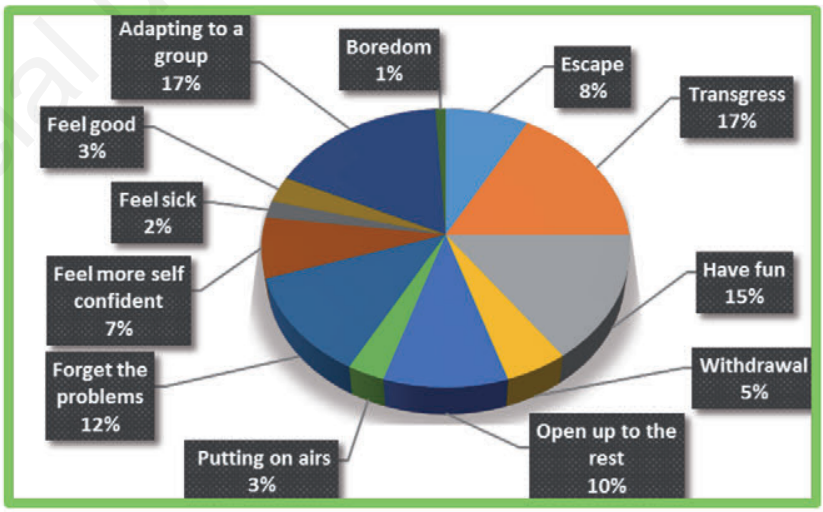

Figure 3. Reason that allow to get drunk.

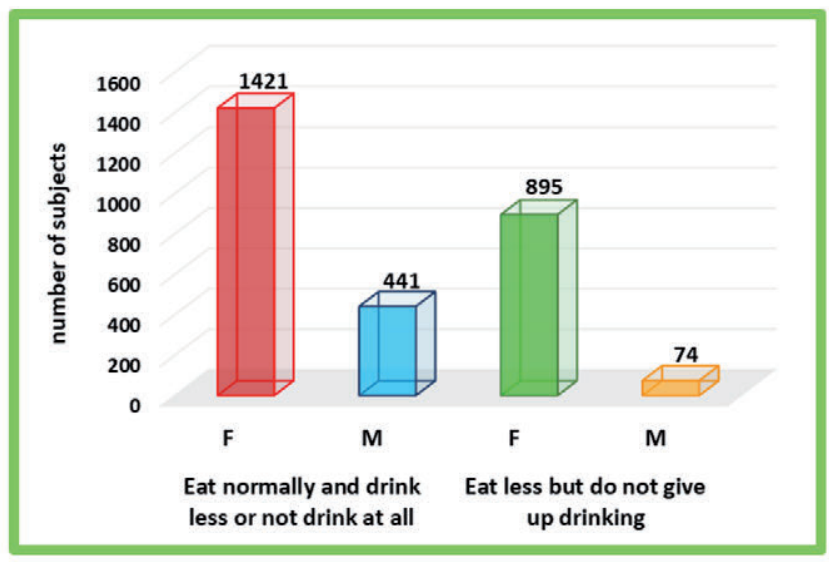

Figure 4. Drunkorexia related-problems diffusion. 
The last important data to analyze is that related to the need to make use of alcohol and drugs during the weekend for having fun. $85 \%$ of adolescents prefer to use alcohol, drugs, and only $15 \%$ of them said no.

\section{Conclusions}

In the light of what emerged from the present survey, it seems evident that there is a massive diffusion among the youth population of correlables to Binge Drinking and Drunkoressia.

Through local and national data, it is possible to find a reduction in the age in which the first contact with alcohol takes place, which falls to 11 years. The motivation that has led to this worsening is linked to increasingly misleading and captivating advertisements, which are made to make alcohol as something safe and fashionable.

It is therefore essential to create adequate monitoring systems. It is necessary to implement actions of primary prevention and health promotion, especially in a very vulnerable band such as adolescents, through: i) Educational campaigns for young people, but also for parents and teachers; ii) Greater surveillance in the premises in order to avoid the sale of alcohol to children under the age of 18; iii) Greater controls by law enforcement agencies to avoid the risk of young drivers driving with high levels of alcohol; iv) Creation of structures that coordinate, promote and implement alcohol prevention policies; v) Increase of prevention and information activities by health professionals.

In conclusion, it would be advisable to deepen this survey by addressing it to a larger sample of adolescents in the territory, in order to monitor the trend of alcohol-related phenomena and thus specifically target the previously reported prevention and information activities.

\section{References}

1. Baiocco R, D'Alessio M, Laghi F. I giovani e l'alcool: il fenomeno del Binge Drinking. Roma: Carocci; 2008.

2. Scafato E, Gandin C, Patussi V. Alcol e Salute. Istituto Superiore di Sanità e Centro Collaboratore OMS; 2012.

3. Kanny D, Liu Y, Brewer RD. Vital signs: binge drinking among high school students and adults. National Center for Chronic Disease Prevention and Health Promotion; 2009.

4. Burke SC, Cremeens J, Vail-Smith K, Woolsey C. Drunkorexia: calorie restriction prior to alcohol consumption among college freshman. J Alcohol Drug Educ 2010;54:17-34.

5. Klaassen C, Watkins JB. Casarett \& Doull Elementi di tossicologia. Casa Editrice Ambrosiana; 2013.

6. Galli CL. Tossicologia. Padova: Piccin; 2016.

7. Bakduini W, Costa GL. Tossicologia applicata ai farmaci. Milano: Edra; 2015.

8. Bernstein J, Heeren T, Edward E, et al. A Brief Motivational Interview in a Pediatric Emergency Department, Plus 10-Day Telephone Follow-Up, Increases Attempts to Quit Drinking Among Youth and Young Adults Who Screen Positive for Problematic Drinking. Acad Emerg Med 2010;17:890-902.

9. Serpelloni G, Alessandrini F, Zoccatelli G, Romano C. Neuroscienze delle Dipendenze: il Neuroimaging, documento sugli effetti dell'uso di alcool sul cervello degli adolescenti. Dipartimento Politiche Antidroga; 2012.

10. World Health Organization. Collaboration Centre for Research and Health Promotion on Alcohol and Alcohol-Related Health Problems. Piano d'azione europeo per ridurre il consumo dannoso di alcol 2012-2020; 2013. 